This is an author produced version of a paper published in Cellular Signalling. This paper has been peer-reviewed but does not include the final publisher proof-corrections or journal pagination.

Citation for the published paper:

Nilsson, Rebecka and Ahmad, Faiyaz and Sward, Karl and Andersson, Ulrika and Weston, Marie and Manganiello, Vincent and Degerman, Eva. "Plasma membrane cyclic nucleotide phosphodiesterase 3B (PDE3B) is associated

with caveolae in primary adipocytes"

Cellular Signalling, 2006, Issue: Feb 24.

http://dx.doi.org/10.1016/j.cellsig.2006.01.010

Access to the published version may require journal subscription.

Published with permission from: Elsevier 


\section{Plasma membrane cyclic nucleotide phosphodiesterase 3B (PDE3B) is associated with caveolae in primary adipocytes}

$\underline{\text { Rebecka Nilsson }}^{\mathrm{a}, *}$, Faiyaz Ahmad $^{\mathrm{b}}$, Karl Swärd ${ }^{\mathrm{a}}$, Ulrika Andersson ${ }^{\mathrm{a}}$, Marie Weston ${ }^{\mathrm{b}}$, Vincent Manganiello ${ }^{\mathrm{b}}$, Eva Degerman ${ }^{\mathrm{a}}$

${ }^{\mathrm{a}}$ Department of Experimental Medical Science, Lund University, BMC C11, 22184 Lund, Sweden

${ }^{\mathrm{b}}$ Pulmonary/Critical Care Medicine Branch, National Heart, Lung, and Blood Institute, NIH, Bethesda, MD, 20892, USA

*Corresponding author: Tel: +46 46 2228587; fax: +46 46 2224022; e-mail:

rebecka.nilsson@med.lu.se 


\begin{abstract}
Caveolae, plasma membrane invaginations particularly abundant in adipocytes, have been suggested to be important in organizing insulin signalling. Insulin-induced activation of the membrane bound cAMP degrading enzyme, phosphodiesterase 3B (PDE3B) is a key step in insulin-mediated inhibition of lipolysis and is also involved in the regulation of insulinmediated glucose uptake and lipogenesis in adipocytes. The aim of this work was to evaluate whether PDE3B is associated with caveolae. Subcellular fractionation of primary rat and mouse adipocytes demonstrated the presence of PDE3B in endoplasmic reticulum and plasma membrane fractions. The plasma membrane PDE3B was further analyzed by detergent treatment at $4^{\circ} \mathrm{C}$, which did not solubilize PDE3B, indicating an association of PDE3B with lipid rafts. Detergent-treated plasma membranes were studied using Superose-6 chromatography which demonstrated co-elution of PDE3B with caveolae and lipid raft markers (caveolin-1, flotillin-1 and cholesterol) at a $\mathrm{Mw}$ of $>4000 \mathrm{kDa}$. On sucrose density gradient centrifugation of sonicated plasma membranes, a method known to enrich caveolae, PDE3B co-migrated with the caveolae markers. Immunoprecipitation of caveolin-1 using anti caveolin-1 antibodies co-immunoprecipitated PDE3B and immunoprecipitation of flagPDE3B from adipocytes infected with a flag-PDE3B adenovirus resulted in coimmunoprecipitation of caveolin-1. Studies on adipocytes with disrupted caveolae, using either caveolin- 1 deficient mice or treatment of adipocytes with methyl- $\beta$-cyclodextrin, reduced the membrane associated PDE3B activity. Furthermore, inhibition of PDE3 in primary rat adipocytes resulted in reduced insulin stimulated glucose transporter-4 translocation to caveolae, isolated by immunoprecipitation using caveolin-1 antibodies. Thus, PDE3B, a key enzyme in insulin signalling, appears to be associated with caveolae in adipocytes and this localization seems to be functionally important.
\end{abstract}

Keywords: PDE3B, caveolae, caveolin-1, adipocytes, insulin, GLUT-4 


\section{Introduction}

Caveolae, which are special forms of lipid rafts observed as small flask-shaped $50-100 \mathrm{~nm}$ invaginations of the plasma membrane, have been suggested to be important in organizing insulin and catecholamine signalling events [1,2]. Although caveolae are observed in many cell types they are particularly abundant in adipocytes. They have a high content of cholesterol and sphingolipids and are stabilized by one or more caveolin isoforms. In adipocytes caveolin-1 is the most prominent [3] isoform and its ablation leads to a total loss of caveolae [4]. Recent work in rat and human adipocytes have shown that the insulin receptor (IR) and insulin receptor substrate (IRS)-1 are localized to caveolae, although there are some disagreements [5-7], and insulin induced phosphorylation of IRS-1 and protein kinase B (PKB) is blunted in 3T3-L1 adipocytes depleted of caveolae [8]. Furthermore, in response to insulin stimulation, it has been show that glucose transporter-4 (GLUT-4) translocates from intracellular vesicles to caveolae [3, 9], although this is somewhat controversial [10].

Caveolin-1 deficient mice which lack caveolae in most tissues show abnormalities in lipid metabolism with elevated triglyceride levels, elevated postprandial free fatty acid levels, and atrophy of white adipose tissue [4]. Furthermore, caveolin-1 deficient mice show a $90 \%$ decrease in IR expression selectively in adipose tissue, greatly reduced insulin-induced phosphorylation of PKB, and insulin resistance [11]. Caveolin-3 deficient mice with a total ablation of caveolae in skeletal muscle have a reduced insulin sensitivity in this tissue [12]. These findings indicate that intact caveolae are important for normal insulin signalling and metabolism of carbohydrates and lipids in adipocytes.

Phosphodiesterase 3B (PDE3B) belongs to a super family of cAMP and cGMP degrading enzymes and is expressed in cells of importance for glucose and lipid metabolism such as adipocytes, hepatocytes and pancreatic $\beta$-cells $[13,14]$. Its role and regulation have been extensively studied in adipocytes where it has been demonstrated to have a key role in insulin-mediated inhibition of lipolysis [13]. PDE3B has recently also been suggested to be involved in the regulation of insulin-induced glucose uptake, GLUT-4 translocation to the plasma membrane, and lipogenesis in adipocytes $[15,16]$. Since caveolae are important in organizing cAMP and insulin signalling pathways we examined whether PDE3B is associated with the caveolae signalling platform and if this association is functionally important. 


\section{Materials and methods}

\subsection{Materials}

Sprague-Dawley rats were purchased from B\&K Universal (Stockholm, Sweden) and C57BL/6 male mice from Taconic (New York, USA). Caveolin-1 deficient (KO) mice on the C57BL/6 background obtained from the Jackson Laboratory (Bar Harbor, Maine) were further backcrossed on the same background and genotyped as described by Razani et al [17]. Dulbecco's modified Eagle's medium (DMEM) and fetal calf serum (FCS) were acquired from GIBCO BRL (Praisley, UK). Insulin was obtained from Novo Nordisk (Copenhagen, Denmark), OPC3911 from Otsuka Pharmaceuticals Co., Ltd (Tokyo, Japan), octyl- $\beta$-Dglucopyranoside from Calbiochem (La Jolla, USA) and $\mathrm{C}_{13} \mathrm{E}_{12}$ from Berol Kemi $\mathrm{AB}$ (Stenungssund, Sweden). The Infinity Cholesterol Liquid Stable Kit was purchased from Thermo Electron (Melbourne, Australia) and Protein A Sepharose 4 fast flow and Superose-6 (10/300) columns from Amersham Pharmacia Biotech AB (Uppsala, Sweden). Antibodies against caveolin-1 (rabbit polyclonal), adenylyl cyclase (AC) V and GLUT-4 (goat polyclonal) were obtained from Santa Cruz Biotechnology; flotillin-1, nucleoporin p62, GM130 and BiP from BD Transduction Laboratories; COX IV from Cell Signaling Technology. Anti-PDE3B antibodies were raised in rabbits against the peptide CGYYGSGKMFRRPSLP from PDE3B (mouse and rat). The adenovirus with flag-tagged PDE3B was produced as described by Härndahl et al [14]. Anti-flag M2 affinity gel, methyl$\beta$-cyclodextrin and, if not otherwise stated, all other chemicals were obtained from SigmaAldrich.

\subsection{Adipocyte preparation, cholesterol extraction and virus infection}

Adipocytes were prepared from epidymal fat pads of 36- to 38-day-old male SpragueDawley rats (B\&K Universal, Stockholm, Sweden) by collagenase digestion [18] with some modifications [19]. Cells (10\% cell suspension) were resuspended in Krebs-Ringer medium (KRH) pH 7.4 containing $25 \mathrm{mM}$ HEPES, $200 \mathrm{nM}$ adenosine, $2 \mathrm{mM}$ glucose, and $1 \%$ bovine serum albumin at $37^{\circ} \mathrm{C}$. To extract cholesterol from plasma membranes, rat adipocytes were incubated in the presence or absence of methyl- $\beta$-cyclodextrin at different concentrations for 50 minutes. To test the effect of PDE3B inhibition on insulin-mediated translocation of 
GLUT-4 to caveolae, cells were incubated with or without the PDE3 inhibitor OPC3911 for 10 min before stimulation with $2 \mathrm{nM}$ insulin alone or together with $30 \mathrm{nM}$ isoproterenol for 10 min. For adenoviral infection rat adipocytes were suspended in DMEM with 5\% FCS and $0.5 \%$ bovine serum albumin ( $12.5 \%$ cell suspension) and infected with flag-tagged murine PDE3B adenovirus (AdPDE3B, $6.5 \times 10^{7} \mathrm{PFU} / \mathrm{ml}$ ) for 12 hours at $37^{\circ} \mathrm{C}$; PDE3B expression was increased 100-fold. Lund University Ethic Committee approved the study, permission number: M170-03.

\subsection{Subcellular fractionation of primary mouse adipocytes on continuous sucrose gradient}

Mouse primary adipocytes were prepared as described above and homogenized in buffer A containing $50 \mathrm{mM}$ HEPES pH 7.5, $50 \mathrm{mM}$ sucrose, $1 \mathrm{mM}$ EDTA, $10 \mathrm{mM}$ pyrophosphate, 5 $\mathrm{mM} \mathrm{NaF}, 100 \mathrm{mM} \mathrm{NaCl}, 1 \mathrm{mM}$ sodium orthovanadate, $1 \mathrm{uM}$ okadaic acid, $1 \mu \mathrm{g} / \mathrm{ml}$ pepstatin A, $10 \mu \mathrm{g} / \mathrm{ml}$ leupeptin and $10 \mu \mathrm{g} / \mathrm{ml}$ antipain with a dounce homogenizer (20-25 strokes). The homogenate was centrifuged (1 $000 \mathrm{xg}, 20 \mathrm{~min}$ ) and the supernatant was collected and centrifuged again (175 $000 \mathrm{xg}, 30 \mathrm{~min}$ ). The pellet was rehomogenized in $1 \mathrm{ml}$ buffer $\mathrm{A}$ and layered on top of a linear 10-45 \% sucrose gradient (11 ml, prepared using J17 Model gradient maker from Jule Inc and confirmed with Palm Abbe digital refractometer) in a SW41 Beckman rotor and centrifuged (40 $000 \mathrm{rpm}, 60 \mathrm{~min}$ ). Each step after the first homogenization was performed at $4^{\circ} \mathrm{C}$.

\subsection{Subcellular fractionation of adipocytes and adipose tissue by sequential centrifugations}

Adipocyte subcellular fractions were prepared according to Simpson et al [20] with modifications as described by Göransson et al [21]. Excised, washed and minced epidymal fat pads from 10-12 weeks old cav- $1^{-/-}$and cav- $1^{+/+}$mice or isolated rat adipocytes $(0.3-0.5 \mathrm{~g}$ or 0.5-1.0 $\mathrm{ml} \mathrm{PCV}$, respectively) were homogenised in $2 \mathrm{ml}$ buffer B, containing $40 \mathrm{mM}$ HEPES pH 7.4, $10 \mathrm{mM} \mathrm{NaF}, 1 \mathrm{mM}$ phenylmethylsulfonylflouride, $0.25 \mathrm{mM}$ sodium orthovanadate, 1 $\mu \mathrm{g} / \mathrm{ml}$ pepstatin A, $10 \mu \mathrm{g} / \mathrm{ml}$ leupeptin and $10 \mu \mathrm{g} / \mathrm{ml}$ antipain, and centrifuged (15 $000 \mathrm{x} \mathrm{g}, 20$ min). The fat cake was removed and the pellet, referred to as the crude plasma membrane fraction, was either resuspended in buffer C (50 mM TES pH 7.4, $50 \mathrm{mM}$ sucrose, $1 \mathrm{mM}$ EDTA, 0,1 mM EGTA, $1 \mu \mathrm{g} / \mathrm{ml}$ pepstatin A, $10 \mu \mathrm{g} / \mathrm{ml}$ leupeptin and $10 \mu \mathrm{g} / \mathrm{ml}$ antipain) and subjected to immunoprecipitation or PDE assay, or resuspended in $1.5 \mathrm{ml}$ buffer B and 
layered on top of a sucrose cushion containing $1.12 \mathrm{M}$ sucrose, $20 \mathrm{mM}$ Tris pH 7.4 and $1 \mathrm{mM}$ EDTA, and centrifuged (104000 x g, $70 \mathrm{~min}$ ). The pellet containing nuclei and mitochondria (N/Mit) was rehomogenized in 200 or $350 \mu \mathrm{l}$ (200 $\mu \mathrm{l}$ for immunoblot analysis, $350 \mu \mathrm{l}$ for Suprose- 6 chromatography) buffer C supplemented with $80 \mathrm{mM} \mathrm{NaCl}, 80 \mathrm{mM} \mathrm{NaF}$ and $1 \%$ $\mathrm{C}_{13} \mathrm{E}_{12}$. The interphase containing plasma membranes (PM) was collected, diluted to $2.5 \mathrm{ml}$ and centrifuged (48 $000 \mathrm{xg}, 45 \mathrm{~min}$ ). The PM pellet was rehomogenized in buffer $\mathrm{C}$ as described for the N/Mit fraction or as indicated below. The supernatant from the first centrifugation step was centrifuged again ( $48000 \mathrm{x} \mathrm{g}, 20 \mathrm{~min}$ ) to obtain a pellet containing high density microsomes (HDM). The supernatant was further centrifuged (216 $000 \mathrm{x} \mathrm{g}, 70$ min) to get a pellet with low density microsomes (LDM) and cytosol. The HDM and LDM fractions were resuspended as described for the N/Mit fraction. Each step after the first homogenization was performed at $4^{\circ} \mathrm{C}$.

\subsection{Superose-6 chromatography}

The PM, HDM and N/Mit fraction (corresponding to $0.4-1.5 \mathrm{ml} \mathrm{PCV}$ ) from rat adipocytes or HDM + PM (corresponding to $1 \mathrm{ml}$ PCV) from rat adipocytes expressing flag-PDE3B were solubilized for $40 \mathrm{~min}$ at $4^{\circ} \mathrm{C}$ and centrifuged $\left(10000 \mathrm{x}\right.$ g for $\left.10 \mathrm{~min}, 4^{\circ} \mathrm{C}\right)$. The supernatants were filtered $(0.2 \mu \mathrm{m}$ pore size $)$ and subjected to gel filtration chromatography on a Superose$6(10 / 300)$ column (separation range, 5-4 $000 \mathrm{kDa})$ in a fast protein liquid chromatography system. The column was equilibrated and eluted with the following buffer: $25 \mathrm{mM}$ HEPES pH 7.4, $150 \mathrm{mM} \mathrm{NaCl}, 1 \mathrm{mM}$ EDTA, $10 \mathrm{mM} \mathrm{Na}_{4} \mathrm{O}_{7} \mathrm{P}_{2}, 5 \mathrm{mM} \mathrm{NaF}, 1 \mathrm{mM}$ PMSF, $1 \mathrm{mM}$ $\mathrm{Na}_{3} \mathrm{VO}_{4}, 1 \mu \mathrm{g} / \mathrm{ml}$ pepstatin $\mathrm{A}, 5 \mu \mathrm{g} / \mathrm{ml}$ leupeptin and $5 \mu \mathrm{g} / \mathrm{ml}$ antipain and $1 \% \mathrm{C}_{13} \mathrm{E}_{12}$, the flow rate was set to $0.5 \mathrm{ml} / \mathrm{min}$ and $0.4 \mathrm{ml}$ fractions were collected. Absorbance at $280 \mathrm{~nm}$ was monitored on-line and gel filtration standards (Bio-Rad) ranging from 1-670 kDa was used.

\subsection{Preparation of caveolae enriched fractions from plasma membranes}

Rat adipocyte PMs (originating from $1.5 \mathrm{ml} \mathrm{PCV}$ ) were resuspended in $1 \mathrm{ml}$ of $0.5 \mathrm{M}$ $\mathrm{Na}_{2} \mathrm{CO}_{3}$ pH 11 with $1 \mu \mathrm{g} / \mathrm{ml}$ pepstatin $\mathrm{A}, 10 \mu \mathrm{g} / \mathrm{ml}$ leupeptin and $10 \mu \mathrm{g} / \mathrm{ml}$ antipain and sonicated with a probe-type sonifier (soniprep 150) 3 x $20 \mathrm{sec}$. The sonicated PMs were thereafter placed in the bottom of a tube and mixed with $1 \mathrm{ml} 90 \%$ sucrose in $25 \mathrm{mM}$ MES 
and $0.15 \mathrm{M} \mathrm{NaCl}$ to yield a final concentration of $250 \mathrm{mM} \mathrm{Na}_{2} \mathrm{CO}_{3}$ and $45 \%$ sucrose. On top of this solution, $4 \mathrm{ml} 35 \%$ sucrose in $25 \mathrm{mM}$ MES, $0.15 \mathrm{M} \mathrm{NaCl}$ and $250 \mathrm{mM} \mathrm{Na}_{2} \mathrm{CO}_{3} \mathrm{pH} 11$ were added. Finally, $4 \mathrm{ml}$ of $5 \%$ sucrose in $25 \mathrm{mM} \mathrm{MES}, 0.15 \mathrm{M} \mathrm{NaCl}$ and $250 \mathrm{mM} \mathrm{Na}_{2} \mathrm{CO}_{3}$ pH 11 were layered on top. The gradient was centrifuged using a SW41 Beckman rotor at $39000 \mathrm{x} \mathrm{g}$ for $18-19 \mathrm{hrs}$ at $4^{\circ} \mathrm{C}$. From the top of the tube, $1 \mathrm{ml}$ fractions were collected. Before PDE3 activity measurements were initiated, $\mathrm{pH}$ was neutralized ( $\mathrm{pH}$ 7-8) using $3.6 \mathrm{M}$ $\mathrm{HCl}(2-8 \mu \mathrm{l})$. Each step was performed at $4^{\circ} \mathrm{C}$.

\subsection{Preparation of detergent resistant PM and immunoprecipitations}

Rat adipocyte PMs (originating from $500 \mu \mathrm{PCV}$ ) were rehomogenised in $0.5 \mathrm{ml}$ buffer C. Triton X-100, CHAPS, D-octyl glycoside [1 \%, $2 \%$ and $60 \mathrm{mM}(1.75 \%)$ final concentrations respectively] were added to $50 \mu \mathrm{l}$ of resuspended PMs to a final volume of $100 \mu \mathrm{l}$. After one hour on ice, the fractions were centrifuged at $104000 \mathrm{x}$ g for $1 \mathrm{~h}$. The pellets containing detergent resistant PM were resuspended in $100 \mu \mathrm{l}$ buffer $\mathrm{C}$ and analyzed. For immunoprecipitations the PM (corresponding to $750 \mu \mathrm{lCV}$ ) resistant to $1 \%$ Triton X-100 treatment were suspended in $300 \mu \mathrm{l}$ buffer $\mathrm{C}$ and incubated for $4 \mathrm{~h}$ with $6 \mu \mathrm{l}$ caveolin-1 antibody supplemented with $10 \mu \mathrm{l}$ packed Protein A Sepharose during the last hour. Nonbound material was removed and the Sepharose gel was washed five times in $600 \mu \mathrm{l}$ buffer C. The bound proteins were eluted by boiling for $15 \mathrm{~min}$ in buffer $\mathrm{C}$ supplemented with $0.6 \%$ $\mathrm{C}_{13} \mathrm{E}_{12}, 48 \mathrm{mM} \mathrm{NaF}, 48 \mathrm{mM} \mathrm{NaCl}, 5 \% \mathrm{SDS}, 2 \% \beta$-mercaptoethanol and $5 \%$ glycerol. Fractions from Superose- 6 chromatography of flag-PDE3B from adipocytes expressing the recombinant protein were incubated with $10 \mu \mathrm{l}$ of anti-flag M2 affinity gel for $5 \mathrm{~h}$. The gel was washed and eluted as described above. For GLUT-4 analysis, crude PM fractions (corresponding to $500 \mu \mathrm{PCV}$ ) were treated with $1 \% \mathrm{C}_{13} \mathrm{E}_{12}$ and centrifuged at $7000 \mathrm{x} \mathrm{g}, 10$ $\min$. The supernatant was incubated for $4 \mathrm{~h}$ with $4 \mu \mathrm{l}$ caveolin- 1 antibody supplemented with $7 \mu l$ packed Protein A Sepharose during the last hour. The gel was washed and eluted as described above. Each step in the immunoprecipitation procedures was performed at $4^{\circ} \mathrm{C}$.

\subsection{PDE assay}

PDE activity was measured, in duplicate, in the presence or absence of $8 \mu \mathrm{M}$ of the PDE3 inhibitor OPC3911, as described previously [22] . The assay was performed at $30^{\circ} \mathrm{C}$ in a total 
volume of $300 \mu$ l containing $50 \mathrm{mM}$ (TES) pH 7.4, $250 \mathrm{mM}$ sucrose, 1 mM EDTA, $0.1 \mathrm{mM}$ EGTA, $8.3 \mathrm{mM} \mathrm{MgCl} 2,0.5 \mathrm{mM}$ cAMP, $1 \mu \mathrm{Ci} / \mathrm{ml}^{3} \mathrm{H}$-cAMP and $0.6 \mu \mathrm{g} / \mathrm{ml}$ ovalbumin.

\subsection{Protein and Cholesterol measurements}

Cholesterol concentrations were determined by measuring the amount of $\mathrm{H}_{2} \mathrm{O}_{2}$ produced by cholesterol oxidase using Infinity cholesterol Liquid stable kit. This assay was optimized for measuring cholesterol in tissue samples. Protein was measured using a bicinchoninic acid (BCA) protein reagent kit from Pierce (Rockford, USA).

\subsection{Immunoblot analysis}

Portions of the fractions prepared as described above were mixed with Laemmli sample buffer and subjected to SDS-polyacrylamide gel electrophoresis (9-12\% acrylamide) before electrotransfer of the proteins to hybond-C extra membranes (Amersham Bioscienses, Buckinghamshire, UK). Membranes were blocked for $1 \mathrm{~h}$ with $8 \%$ milk in $20 \mathrm{mM}$ Tris $\mathrm{pH}$ 7.6, $137 \mathrm{mM} \mathrm{NaCl}$, and $0.1 \%$ Tween-20 before incubation with PDE3B, AC, Nucleoporin p62, COX IV, GM130, BIP or GLUT-4 antibodies over night and Flotillin-1 or caveolin-1 antibodies for 1-2 $\mathrm{h}$. The analysis was performed using Super Signal reagents (Pierce, Rockford, USA) and a CCD camera (LAS 1000 Plus, Fuji, Tokyo, Japan).

\subsection{Statistical Analysis}

Data are given as the mean values \pm standard error of mean (SEM) of the indicated number of experiment. The statistical significance of differences was counted using the nonparametric Wilcoxon Signed Rank test. 


\section{Results}

\subsection{Rat adipocyte PDE3B is associated with detergent resistant plasma membranes}

In order to establish the localization of adipocyte PDE3B we used two different methods for subcellular fractionation, which we applied to primary adipocytes (from mouse and rat). Mouse primary adipocyte membranes were subjected to continuous sucrose gradient (10-45 $\%$ ) centrifugation to separate different subcellular fractions. As seen in figure 1a, PDE3B was found in the plasma membrane (PM), endoplasmic reticulum (ER) and golgi apparatus (Golgi) enriched fractions, based on the distribution of the PM markers caveolin-1 and adenylyl cyclase V, the ER marker BiP and the Golgi marker GM130. To isolate subcellular fractions from rat adipocytes we used a discontinuous sucrose gradient in combination with sequential centrifugations. Five subcellular fractions were isolated; cytosol, PM, nuclei/mitochondria (N/Mit), high density membranes (HDM) enriched in ER and low density membranes (LDM) enriched in the Golgi. As seen in figure 1b, PDE3B is enriched mainly in the PM and HDM fractions but also to some extent in the N/Mit fraction in rat primary adipocytes. Thus, basically the same results were obtained utilizing two independent separation methods and adipocyte sources. In the following we further characterized the rat adipocyte PDE3B.

To evaluate if PDE3B is associated with other proteins in the different fractions the PM, $\mathrm{HDM}$ and N/Mit fractions were treated with $1 \% \mathrm{C}_{13} \mathrm{E}_{12}$ and subjected to Superose- 6 chromatography (separation range from 5 to $4000 \mathrm{kDa}$ ). As seen in figure 2a, PDE3B in the plasma membrane fraction mainly eluted as a high Mw peak, corresponding to the void volume, here referred to as the $>4000 \mathrm{kDa}$ peak. On the other hand, in the N/Mit and HDM fractions, PDE3B eluted to a much larger extent in a peak corresponding to a $\mathrm{Mw}$ of $670 \mathrm{kDa}$ (five times its own $\mathrm{Mw}, 135 \mathrm{kDa}$ ). These results suggest that the PM derived PDE3B is organized into very large molecular assemblies. We wanted to further examine if these assemblies could be lipid rafts. Lipid rafts and a subpopulation of lipid rafts, caveolae, are particularly abundant in adipocyte PM and are much more resistant to solubilization by nonionic detergents than are non-raft membranes. Detergent treatment of adipocyte PM, followed by centrifugation, immunoblot analysis, and PDE3B activity measurements showed that PDE3B followed the solubilization pattern of caveolin-1 (figure 2b). PDE3B and caveolin-1 in the PM were to a large extent resistant to the non-ionic detergents, $1 \%$ Triton X-100 or 2 $\%$ CHAPS, known to selectively solubilize non-raft markers at $4^{\circ} \mathrm{C}[23]$. On the other hand 
treatment with $60 \mathrm{mM}$ octyl glycoside, a non-ionic detergent known to efficiently solubilize raft associated proteins but not the cytoskeleton or other insoluble protein complexes [23] resulted in solubilization of most PDE3B and caveolin-1 (figure 2b). The estimated enrichment of PDE3B (PDE3 activity/protein content) in the non-solubilized fraction after treatment with $1 \%$ Triton X-100 or $2 \%$ CHAPS was approximately 3 -fold. These results support that PDE3B in the PM is part of a large molecular assembly ( $>4000 \mathrm{kDa})$, which may be caveolae. In contrast, the $670 \mathrm{kDa}$ peak may represent association of PDE3B with a distinct macromolecular assembly without caveolae as an organizing platform. In the following, the PM PDE3B is further analyzed.

\subsection{PDE3B is associated with caveolae}

The fractions from Superose- 6 chromatography of PM from primary rat adipocytes were further analyzed for the caveolae marker protein caveolin-1, lipid raft marker protein flotillin1 , and for cholesterol which is highly enriched in lipid rafts and caveolae. As shown in figure $3 \mathrm{a}$ and $\mathrm{b}$, cholesterol as well as caveolin-1 and flotillin-1 co-eluted with PDE3B during Superose- 6 chromatography, supporting the association of PDE3B with caveolae in the $>4000 \mathrm{kDa}$ peak.

With the use of sucrose gradient centrifugation it is possible to separate caveolae from other membrane structures without using detergent, resulting in the isolation of caveolae from adipocyte PM with high purity [24, 25]. After sucrose gradient centrifugation of sonicated PM a milky band was detected (fraction 5, figure 4). As shown in figure $4 \mathrm{a}$ and $\mathrm{b}$ the caveolae marker protein caveolin-1 and lipid raft marker protein flotillin-1 as well as cholesterol were found in fraction 5 together with PDE3B, supporting an association of PDE3B with caveolae. Co-migration of PDE3B with the caveolae and lipid raft markers also occurred using detergent resistant PM (PM not soluble in $1 \%$ Triton X-100) as starting material for sucrose gradient centrifugation (data not shown).

To further investigate the association of PDE3B with the caveolae marker caveolin-1, caveolin-1 antibodies were used to immunoisolate caveolae from $1 \%$ Triton-X-100 treated adipocyte PM. The detergent resistant PM:s were mixed with caveolin-1 antibodies, the immunocomplexes were isolated, and non-binding material as well as the immunoprecipitate were analyzed using immunoblot analysis with PDE3B and caveolin-1 antibodies (figure 5a). Approximately $30 \%$ of the caveolin- 1 protein immunoprecipitated together with $20 \%$ of the PDE3B protein. This strongly supports association of PDE3B with caveolae. Figure $5 \mathrm{~b}$ shows 
the Superpose-6 elution profile of PDE3B in a detergent treated membrane fraction (PM + HDM) derived from adipocytes over expressing flag-PDE3B. Flag-PDE3B eluted, as was the case for endogenous PDE3B, as two peaks, one at $>4000 \mathrm{kDa}$ and one at $670 \mathrm{kDa}$. As seen in figure 5c, caveolin-1 co-immunoprecipitated with flag-PDE3B using anti-flag antibodies in the $>4000 \mathrm{kDa}$ peak but not in the $670 \mathrm{kDa}$ peak.

\subsection{Importance of caveolae for PDE3B expression and activity}

To study the importance of caveolae for PDE3B activity, caveolae were ablated using two different approaches. First, caveolae were disrupted by treating primary rat adipocytes with methyl- $\beta$-cyclodextrin (cyclodextrin), an agent known to remove cholesterol from the PM and thereby causing flattening of caveolae. Adipocytes treated with 2-3 mM cyclodextrin have a $40 \%$ reduction of cholesterol and treatment with 5-6 mM cyclodextrin reduce the cholesterol by $60 \%$ which, according to Gustavsson et al [5], results in total ablation of caveolae. As shown in figure 6a, PDE3 activity in crude plasma membrane fractions (PM + N/Mit) from rat adipocytes treated with increasing concentrations of cyclodextrin was reduced by $40 \%$, indicating that the cholesterol and caveolae environment are important for PDE3B activity and/or stability. Another model used for studying the effect of caveolae removal on PDE3B activity in adipocytes was the cav-1/- mice in which the caveolin-1 gene is inactivated. In PM from cav $^{-1 /}{ }^{-1}$ adipose tissue the PDE3B activity and protein expression were reduced by $30 \%$ and $75 \%$ respectively as compared to cav- $1^{+/+} \mathrm{PM}$ (figure $6 \mathrm{~b}, \mathrm{c}$ ). Expression of the lipid raft marker flotillin-1, did not vary between cav- $1^{-/}$and cav- $1^{+/+}$adipose tissue PMs (figure $6 \mathrm{c}$ ). Also when ER was isolated from cav-1/- mice adipose tissue, PDE3B activity was reduced as compared to cav- $1^{+/+}$(figure $6 \mathrm{~b}$ ). Thus, either acute or permanent disruption of caveolae results in a reduction of PDE3B activity.

\subsection{Inhibition of PDE3B in adipocytes results in reduced insulin-induced translocation of GLUT-4 to caveolae.}

We have previously shown that inhibition of PDE3B in adipocytes results in reduced insulininduced glucose uptake and reduced translocation of GLUT-4 to the PM [15]. Furthermore, GLUT-4 has been shown to translocate to caveolae in response to insulin stimulation [3, 9]. In agreement with these results, the amount of GLUT-4 associated with caveolae (immunoisolated using caveolin-1 antibodies) was lower in adipocytes treated with insulin in 
combination with OPC3911 or OPC3911 and isoproterenol (a cAMP increasing agent) as compared to insulin alone (figure 7). 


\section{Discussion}

In this report we present evidence, using a number of different methods, that PDE3B is associated with caveolae, an abundant structure in adipocyte PM, with an important role in signalling. PM PDE3B was detergent resistant, a well known characteristic for proteins associated with lipid rafts/caveolae, and enriched 3-fold in the fractions of non-solubilized PM containing caveolin-1 as compared to total PM fractions. Furthermore, PDE3B as well as caveolin-1 and flotillin-1, were detected in the same fraction during sucrose density centrifugation, and a distinct association of PDE3B with caveolin-1 was demonstrated using co-immunoprecipitation. Also, when the PM fraction was subjected to Superose-6 chromatography, most of the PM PDE3B eluted at a Mw $>4000 \mathrm{kDa}$. On the other hand, PDE3B eluted at $670 \mathrm{kDa}$ when ER and N/Mit enriched fractions were analyzed. Thus, we propose that the majority of the PM PDE3B is localized to caveolae and that the $>4000 \mathrm{kDa}$ peak contain major caveolae constituents, as suggested by the detection of caveolae markers specifically in this peak.

The presence of PDE3B in high Mw complexes during gelfiltration of detergent treated adipocyte membranes can, except for its association with caveolae, also be explained by interactions of PDE3B with other proteins. Especially, the $670 \mathrm{kDa}$ peak which is most prominent in the ER fraction does not contain the protein caveolin-1 and could represent PDE3B associated with proteins residing in the ER compartment. Some possible interaction partners of PDE3B have been reported. In adipocytes PDE3B has been shown to interact with the insulin receptor [26], 14-3-3 proteins [27] and a $50 \mathrm{kDa}$ protein [28], and in mouse heart PDE3B has been reported to interact with phosphoinositol 3-kinase $\gamma$ [29]. Our finding that PDE3B co-immunoprecipitates with caveolin-1 gives rise to two possibilities; either that coimmunoprecipitation is obtained due to the co-localization of the two proteins to caveolae or due to direct interaction between PDE3B and caveolin-1. It is interesting to note that PDE3B has two possible caveolin binding motifs ( $\mathrm{X} Ф \mathrm{XXXX} \Phi$, were $\mathrm{X}$ is any amino acid and $\Phi$ represents an aromatic amino acid [30]), one at the N-terminal of PDE3B [aa 54-61 (rat)] and the other after the membrane spanning domain [aa 314-321 (rat)]. We found that disruption of caveolae, either acutely using cyclodextrin or chronically (cav-1 $1^{-/-}$mice) results in lowering of membrane associated PDE3B, suggesting a stabilizing/activating effect of caveolin-1 or other components of caveolae such as cholesterol on PDE3B activity and/or expression. This could be the result from a direct interaction of PDE3B with caveolin-1 or other constituents of caveolae. Most of the proteins known to interact with caveolin-1 seem to be inhibited by this 
interaction although there are exceptions. For example it has been shown that caveolin-1 and 3 can bind to and activate the insulin receptor [31] and that caveolin-1 may have a stabilizing effect on the expression of the insulin receptor [11].

From previous results it is established that PDE3B is membrane associated [32]. The region in PDE3B responsible for this association has been identified [33]. Furthermore, it has been shown that the membrane associated N-terminal part of PDE3B is important for complex formation of PDE3B as judged from analysis using gelfiltration. At this point, it is not possible to be certain as to the relative amounts of PDE3B in PM and internal membrane fractions, since slightly different results have been obtained. In primary rat adipocytes, subcellular fractionation resulted in the enrichment of PDE3B in ER but also to some extent in PM fractions [32]. In 3T3-L1 adipocytes, using immunohistochemistry, PDE3B was found to be mainly localized to ER [33], however, also to some extent to PMs. These previous results are mainly in agreement with our results, although differences with regard to relative proportions of PDE3B in one or the other location/fraction can be noted, and may be related to differences in total recoveries of the various fractions by the different procedures or to differences in cross-contamination of the fractions. The finding that PDE3B is localized to PM as well as ER is interesting to note especially since caveolae seem to have a role in membrane trafficking and lipid transport between PM and ER. In different studies it has been shown that caveolae transport cholesterol from PM to ER and back again, probably to supply the PM with newly synthesized cholesterol [34]. One could speculate that PDE3B also can be transported in caveolae between the ER and PM.

During the past several years, caveolae have become more and more established as an important platform to initiate, organize and generate specificity to intracellular signalling. For example, signalling components mediating effects of insulin and $\beta$-adrenergic agonists have been localized to these structures and the integrity of caveolae has been demonstrated to be important for insulin signalling. Thus, although there are some disagreements, the IR and IRS-1 seem to be localized to caveolae in adipocytes, and insulin-induced activation of downstream kinases like PI3-K and PKB are impaired by caveolae disruption. Furthermore, components known to be activated after catecholamine stimulation such as the $\beta$-adrenergic receptors, adenylyl cyclase (AC) and protein kinase A (PKA) are localized to caveolae [35, 36]. The finding that the cAMP degrading enzyme PDE3B, an enzyme that is phosphorylated and activated by insulin as well as catecholamines, is localized to caveolae is also interesting in the context of regulating local cAMP fluxes. Thus, caveolae could further add to the complexity of compartmentalized cAMP signalling. 
Biological responses known to be critically dependent upon cAMP are catecholamineinduced lipolysis (increases in CAMP) and insulin-induced antilipolysis (decreases in cAMP by PDE3B). Furthermore, a cAMP pool regulated by PDE3B was recently shown to regulate insulin-mediated glucose uptake and translocation of GLUT-4 to the PM [15]. In this work we extend these studies and show that inhibition of PDE3B results in reduced translocation of GLUT-4 to caveolae, indicating that PDE3B is important for caveolae localized insulin signalling events. In support of these results are studies in adipocytes showing that GLUT-4 translocate into caveolae $[3,9]$ in response to insulin stimulation and that cyclodextrin reduces insulin-induced glucose uptake in a dose dependant manner [8, 37]. Attempts to study the role of caveolae in insulin-induced antilipolysis, a process dependent upon activation of PDE3B, were made using adipocytes depleted of caveolae. It was not possible to draw any conclusions from these studies with regard to the ability of insulin to inhibit lipolysis since catecholamine-induced lipolysis was reduced by $80-90 \%$ in adipocytes depleted of caveolae (results not shown), which is in agreement with previous studies [36]. Whether or not PDE3B interacts directly with insulin and catecholamine signalling components or whether a close proximity between PDE3B and these components via caveolae platforms regulate signal transduction is under investigation. To this end we have found immunoreactive GLUT-4, 143-3 proteins, IRS-1 and phosphorylated PKB in the $>4000 \mathrm{kDa}$ peak and pull-down assays are being performed to identify and analyze these interactions (manuscript in preparation, Ahmad et al).

In summary, we have shown that PDE3B, an important enzyme in the regulation of adipocyte metabolic events, is localized to caveolae as well as to ER and that inhibition of PDE3B has impact on insulin mediated translocation of GLUT-4 to caveolae. Ongoing studies aim at further evaluating the role of PDE3B at these different locations.

\section{Acknowlegements}

This work was supported by the Swedish Research Council Project 3362 to Eva Degerman; Swedish Diabetes Association; A. Påhlsson and Dr. P. Håkansson's foundations; Novo Nordisk, Denmark; the Swedish Society of Medicine; The Royal Physiographic Society in Lund. Caveolin-1 deficient mice were bred within the Vascular Wall Program at LU with support from Ragnar Söderberg's Stiftelse. 


\section{REFERENCES}

[1] Cohen AW, Combs TP, Scherer PE, Lisanti MP. Am J Physiol Endocrinol Metab 2003;285(6):E1151-1160.

[2] Ostrom RS, Insel PA. Br J Pharmacol 2004;143(2):235-245.

[3] Scherer PE, Lisanti MP, Baldini G, Sargiacomo M, Mastick CC, Lodish HF. J Cell Biol 1994;127(5):1233-1243.

[4] Razani B, Combs TP, Wang XB, Frank PG, Park DS, Russell RG, Li M, Tang B, Jelicks LA, Scherer PE, Lisanti MP. J Biol Chem 2002;277(10):8635-8647.

[5] Gustavsson J, Parpal S, Karlsson M, Ramsing C, Thorn H, Borg M, Lindroth M, Peterson KH, Magnusson KE, Stralfors P. Faseb J 1999;13(14):1961-1971.

[6] Souto RP, Vallega G, Wharton J, Vinten J, Tranum-Jensen J, Pilch PF. J Biol Chem 2003;278(20):18321-18329.

[7] Karlsson M, Thorn H, Danielsson A, Stenkula KG, Ost A, Gustavsson J, Nystrom FH, Stralfors P. Eur J Biochem 2004;271(12):2471-2479.

[8] Parpal S, Karlsson M, Thorn H, Stralfors P. J Biol Chem 2001;276(13):9670-9678.

[9] Karlsson M, Thorn H, Parpal S, Stralfors P, Gustavsson J. Faseb J 2002;16(2):249251.

[10] Kandror KV, Stephens JM, Pilch PF. J Cell Biol 1995;129(4):999-1006.

[11] Cohen AW, Razani B, Wang XB, Combs TP, Williams TM, Scherer PE, Lisanti MP. Am J Physiol Cell Physiol 2003;285(1):C222-235.

[12] Oshikawa J, Otsu K, Toya Y, Tsunematsu T, Hankins R, Kawabe J, Minamisawa S, Umemura S, Hagiwara Y, Ishikawa Y. Proc Natl Acad Sci U S A 2004;101(34):12670-12675.

[13] Shakur Y, Holst LS, Landstrom TR, Movsesian M, Degerman E, Manganiello V. Prog Nucleic Acid Res Mol Biol 2001;66:241-277.

[14] Harndahl L, Jing XJ, Ivarsson R, Degerman E, Ahren B, Manganiello VC, Renstrom E, Holst LS. J Biol Chem 2002;277(40):37446-37455.

[15] Zmuda-Trzebiatowska E, Oknianska A, Manganiello V, Degerman E. Cell Signal 2006;18(3):382-390.

[16] Eriksson JW, Wesslau C, Smith U. Biochim Biophys Acta 1994;1189(2):163-167.

[17] Razani B, Engelman JA, Wang XB, Schubert W, Zhang XL, Marks CB, Macaluso F, Russell RG, Li M, Pestell RG, Di Vizio D, Hou H, Jr., Kneitz B, Lagaud G, Christ GJ, Edelmann W, Lisanti MP. J Biol Chem 2001;276(41):38121-38138.

[18] Rodbell M. J Biol Chem 1964;239:375-380.

[19] Honnor RC, Dhillon GS, Londos C. J Biol Chem 1985;260(28):15122-15129.

[20] Simpson IA, Yver DR, Hissin PJ, Wardzala LJ, Karnieli E, Salans LB, Cushman SW. Biochim Biophys Acta 1983;763(4):393-407.

[21] Goransson O, Wijkander J, Manganiello V, Degerman E. Biochem Biophys Res Commun 1998;246(1):249-254.

[22] Manganiello VC, Murad F, Vaughan M. J Biol Chem 1971;246(7):2195-2202.

[23] Shogomori H, Brown DA. Biol Chem 2003;384(9):1259-1263.

[24] Ortegren U, Karlsson M, Blazic N, Blomqvist M, Nystrom FH, Gustavsson J, Fredman P, Stralfors P. Eur J Biochem 2004;271(10):2028-2036.

[25] Aboulaich N, Vainonen JP, Stralfors P, Vener AV. Biochem J 2004;383(Pt 2):237248.

[26] Rondinone CM, Carvalho E, Rahn T, Manganiello VC, Degerman E, Smith UP. J Biol Chem 2000;275(14):10093-10098.

[27] Onuma H, Osawa H, Yamada K, Ogura T, Tanabe F, Granner DK, Makino H. Diabetes 2002;51(12):3362-3367. 
[28] Onuma H, Osawa H, Ogura T, Tanabe F, Nishida W, Makino H. Biochem Biophys Res Commun 2005;337(3):976-982.

[29] Patrucco E, Notte A, Barberis L, Selvetella G, Maffei A, Brancaccio M, Marengo S, Russo G, Azzolino O, Rybalkin SD, Silengo L, Altruda F, Wetzker R, Wymann MP, Lembo G, Hirsch E. Cell 2004;118(3):375-387.

[30] Couet J, Li S, Okamoto T, Ikezu T, Lisanti MP. J Biol Chem 1997;272(10):65256533.

[31] Yamamoto M, Toya Y, Schwencke C, Lisanti MP, Myers MG, Jr., Ishikawa Y. J Biol Chem 1998;273(41):26962-26968.

[32] Kono T, Robinson FW, Sarver JA. J Biol Chem 1975;250(19):7826-7835.

[33] Shakur Y, Takeda K, Kenan Y, Yu ZX, Rena G, Brandt D, Houslay MD, Degerman E, Ferrans VJ, Manganiello VC. J Biol Chem 2000;275(49):38749-38761.

[34] Liu P, Rudick M, Anderson RG. J Biol Chem 2002;277(44):41295-41298.

[35] Smart EJ, Graf GA, McNiven MA, Sessa WC, Engelman JA, Scherer PE, Okamoto T, Lisanti MP. Mol Cell Biol 1999;19(11):7289-7304.

[36] Cohen AW, Razani B, Schubert W, Williams TM, Wang XB, Iyengar P, Brasaemle DL, Scherer PE, Lisanti MP. Diabetes 2004;53(5):1261-1270.

[37] Venugopal J, Hanashiro K, Yang ZZ, Nagamine Y. Proc Natl Acad Sci U S A 2004;101(49):17120-17125. 


\section{Figure 1: Subcellular localization of PDE3B in primary mouse and rat adipocytes}

(a) Primary mouse adipocyte total membranes (2.8 $\mathrm{mg}$ protein) were subjected to continuous $10-45 \%$ sucrose gradient centrifugation as described in "materials and methods". 17 portions equal in size were collected and analyzed by immunoblotting. (b) Primary rat adipocytes were subjected to subcellular fractionation by sequential centrifugations as described in "materials and methods". Portions corresponding to $32 \mu \mathrm{l}$ packed cell volume (PCV) were analyzed by immunoblotting. PM; plasma membrane, HDM; high density membranes enriched in Golgi, LDM; low density membranes enriched in endoplasmic reticulum (ER), N/Mit; nuclei and mitochondria, Cyt; cytosol,. Antibodies against the following proteins were used; PDE3B, caveolin-1 (Cav-1), adenylyl cyclase V (AC V, marker for PM), BiP (marker for ER), GM130 (marker for Golgi), COX IV (marker for mitochondria) and nucleoporin p62 (marker for the nucleus). Representative immunoblots are shown $(n=4)$.

\section{Figure 2: PDE3B associates with detergent resistant plasma membranes}

(a) Superose-6 chromatography was carried out on isolated and detergent-treated plasma membrane (PM), nuclei/mitochondria (N/Mit), and high density membrane (HDM) fractions from primary rat adipocytes $(0.5 \mathrm{ml} \mathrm{PCV})$. Fractions $(0.4 \mathrm{ml})$ were collected and analyzed for PDE3 activity and protein content. Shown is a representative experiment $(n=5) . V_{o}$, indicates the void volume, i.e. $>4000 \mathrm{kDa}$. Mw markers, thyroglobulin (670 kDa), gamma globulin $(158 \mathrm{kDa})$, myoglobin $(17 \mathrm{kDa})$ are indicated. Of total proteins in the samples $80 \%$ eluted in a broad peak between 50-200 $\mathrm{kDa}$ (13-17 ml). (b) PM from primary adipocytes ( $0.1 \mathrm{ml} \mathrm{PCV}$ ) were treated with $2 \%$ CHAPS, $1 \%$ Triton X-100 (Triton) or $60 \mathrm{mM}$ octyl glucoside (OG) at $4^{\circ} \mathrm{C}$. The detergent resistant membranes (DRM) and starting material (detergent treated but not centrifuged) (Ctrl) were analyzed using PDE3 activity measurements (lower panel) and immunoblotting (upper panels, $50 \mu \mathrm{l}$ PCV/lane) with antibodies against PDE3B and caveolin1 (Cav-1). The proportion of non-solubilized PDE3 activity compared to starting material was calculated in each experiment with duplicates. Shown is the mean $\pm \operatorname{SEM}(n=4)$. 
Figure 3: PDE3B co-migrates with cholesterol, caveolin-1 and flotillin-1 during gel

\section{filtration}

Suprose- 6 chromotography was carried out on detergent-treated plasma membranes from primary rat adipocytes $(0.5 \mathrm{ml} \mathrm{PCV})$, see figure 1a. Fractions were collected $(0.4 \mathrm{ml})$ and subjected to (a) cholesterol measurements or (b) immunoblot analysis using antibodies toward PDE3B, caveolin-1 (Cav-1) and flotillin-1 (Flot-1). Shown is a representative experiment $(n=4)$.

\section{Figure 4: PDE3B, caveolin-1 and cholesterol co-migrate in caveolae enriched fractions}

PM from sonicated primary rat adipocyte $(0.5 \mathrm{ml} \mathrm{PVC})$ were subjected to sucrose gradient centrifugation as described in "materials and methods". Ten $1 \mathrm{ml}$ fractions were collected starting from the top. The fractions were (a) analyzed for cholesterol or PDE3 activity after $\mathrm{pH}$-adjustment and (b) subjected to immunoblot analysis using antibodies against PDE3B, caveolin-1 (Cav-1) and flotillin-1 (Flot-1). Shown is a representative experiment ( $\mathrm{n}=3$ ).

\section{Figure 5: Caveolin-1 and PDE3B co-immunoprecipitates}

(a) Detergent treated (1\% Triton X-100) PM from primary rat adipocytes were incubated with caveolin-1 (Cav-1) antibodies and precipitated using protein A sepharose. Starting material (Start) and non- immunoprecipitated material (FT) corresponding to $75 \mu 1 \mathrm{PCV}$ and immunoprecipitates (IP) corresponding to $750 \mu \mathrm{PCV}$ were subjected to immunoblot analysis using antibodies against PDE3B and caveolin-1. Positive PDE3B control (Pos); total crude adipocyte membranes, negative control (Neg); adipocyte cytosol. (b) Superose-6 chromatography of detergent treated PM + HDM from primary adipocytes over expressing adenoviral flag-PDE3B was performed. Fractions $(0.4 \mathrm{ml})$ were collected and analyzed for PDE3 activity. $\mathrm{V}_{\mathrm{o}}$ indicates the void volume i.e. $>4000 \mathrm{kDa}$ in size. The elution of $\mathrm{Mw}$ markers, thyroglobulin $(670 \mathrm{kDa})$, gamma globulin $(158 \mathrm{kDa})$ and myoglobin $(17 \mathrm{kDa})$ are indicated in the figure. (c) Three fractions were selected for immunoprecipitation, one from the $>4000 \mathrm{kDa}$ peak (elution volume $7 \mathrm{ml}$ ), one from the $670 \mathrm{kDa}$ peak (elution volume 12 $\mathrm{ml}$ ), and one negative control (elution volume $20 \mathrm{ml}$ ). Anti-flag M2 affinity gel was added to the different fractions. Proteins bound to the gel (IP), the starting material (Start) and nonbound material (FT) were analyzed using immunoblotting with antibodies against caveolin-1 and PDE3B. Start and FT correspond to $15 \mu \mathrm{PCV}$ and IP corresponds to $150 \mu \mathrm{lPCV}$. A representative experiment is shown $(\mathrm{n}=3)$. 
Figure 6: Disruption of caveolae is associated with reduced PDE3B activity/expression

(a) Primary rat adipocytes were treated for 50 min with different concentrations of methyl- $\beta$ cyclodextrin (cyclodextrin) as indicated. A crude plasma membrane fraction $(\mathrm{PM}+\mathrm{N} / \mathrm{Mit})$ was isolated and PDE3 activity measured. In each experiment double samples were prepared and activity was measured. The results are shown as $\%$ of $0 \mathrm{mM}$ cyclodextrin [39.2-106.6 $\mathrm{pmol} / \mathrm{min} / \mathrm{ml}$ PCV after cyclodextrin treatment] ( $<<0.020, \mathrm{p}<0.002, \mathrm{n}=5$ ). (b) PM and ER from cav- $1^{+/+}$and cav- $1^{-/}$adipose tissue were analyzed for PDE3 activity $(\mathrm{p}<0.012$ and $\mathrm{n}=8$ for PM, $\mathrm{p}<0.028$ and $\mathrm{n}=6$ for ER). (c) PDE3B and flotillin-1 (lipid raft marker) expression in PM from cav- $\mathrm{I}^{+/+}$and cav- $\mathrm{I}^{-/ /}$adipose tissue were examined using immunoblot analysis with antibodies against PDE3B and flotillin-1 (Flot-1). A representative experiment is shown (0.6 $\mathrm{mg}$ protein/lane, $\mathrm{n}=3$ ). Data are presented as mean $\pm \mathrm{SEM}$.

\section{Figure 7: Inhibition of PDE3 decreases insulin-induced translocation of GLUT-4 to caveolae}

Primary rat adipocytes was stimulated with $2 \mathrm{nM}$ insulin (Ins) for 10 min with or without pretreatment with $10 \mu \mathrm{M}$ OPC3911 (Ins + OPC) or $30 \mathrm{nM}$ isoproterenol and $10 \mu \mathrm{M}$ OPC3911 (Ins + OPC + Iso). After homogenization and isolation of a crude PM fraction, caveolae were isolated by immunoprecipitation with an antibody against caveolin-1. (a) The immunoprecipitates were subjected to immunoblot analysis using antibodies against GLUT-4 and caveolin-1 (Cav-1). Positive GLUT-4 control (Pos); membrane homogenate of insulin stimulated adipcytes, negative control (Neg); caveolin-1 antibody. A representative experiment is shown ( $\mathrm{n}=7$ ). (b) Quantification of the GLUT-4 and caveolin-1 immunoreactive bands were made by using Fuji LAS 1000 Plus system and the GLUT-4 /caveolin-1 ratios were determined. The ratios are presented as fold increase in comparison to control, mean \pm SEM ( $\mathrm{p}<0.028$ for Ctrl vs. Ins, $\mathrm{p}<0.028$ for Ins vs. Ins + OPC, $\mathrm{p}<0.047$ for Ins vs. Ins + Iso + OPC, $n=7)$. 
Figure 1

a

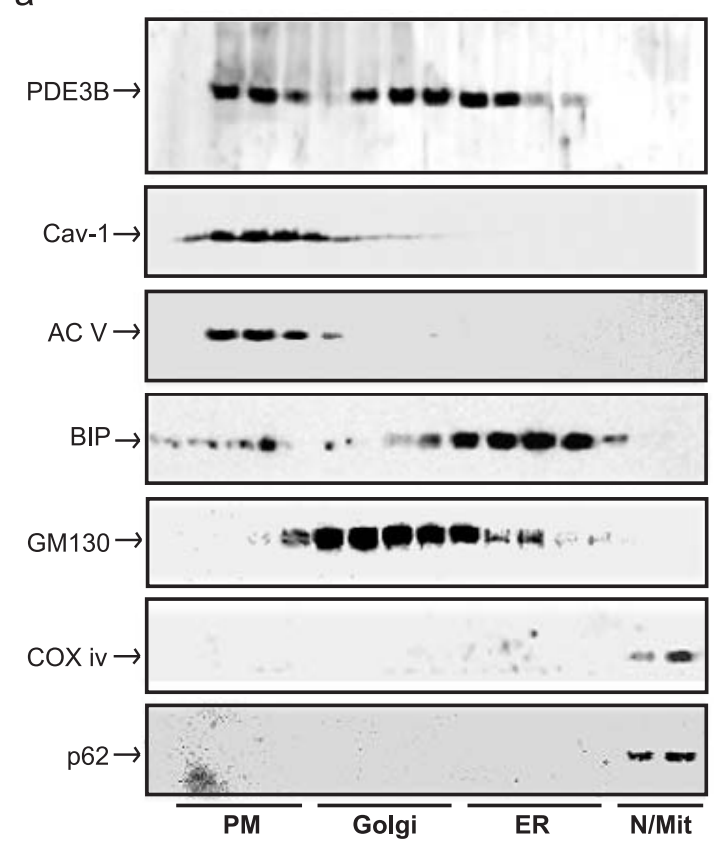

b

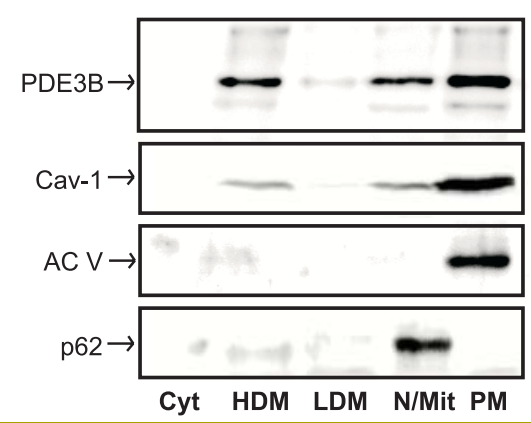


Figure 2

a

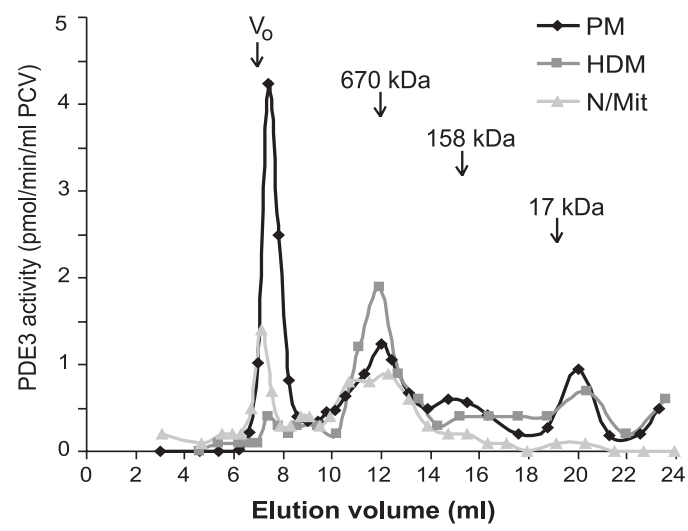

b
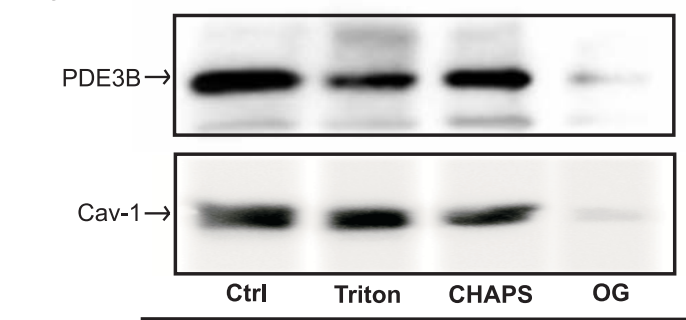

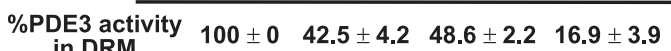

in DRM 
Figure 3

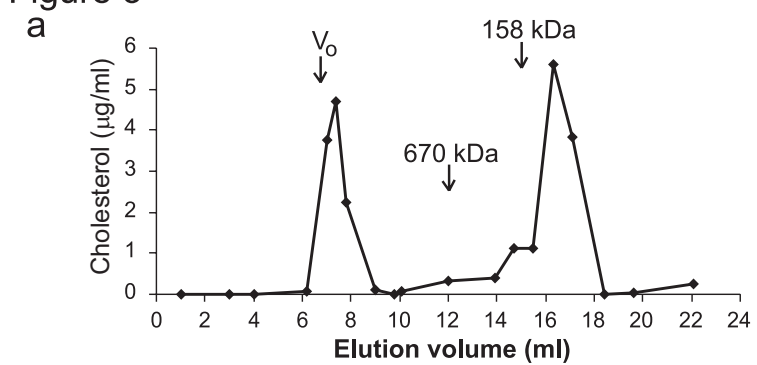

b

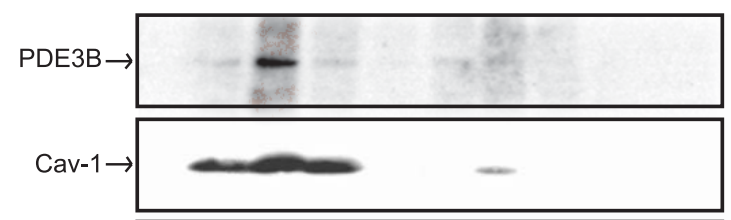

Flot-1

$\begin{array}{llllllllll}\text { volume }(\mathrm{ml}): 6.2 & 7.0 & 7.4 & 7.8 & 9.4 & 11.4 & 12.2 & 13.0 & 17.4 & 20.2\end{array}$ 
Figure 4

a

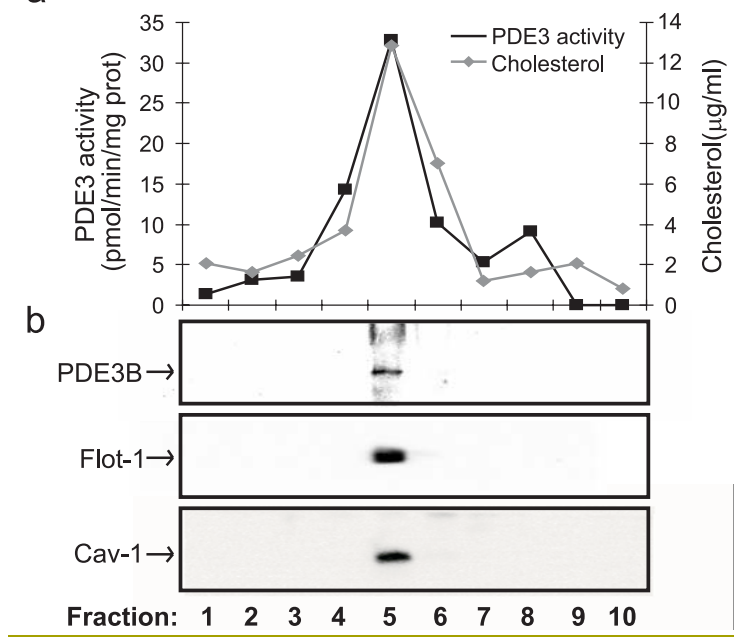


Figure 5

a

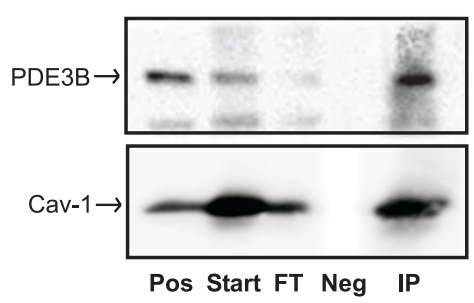

b

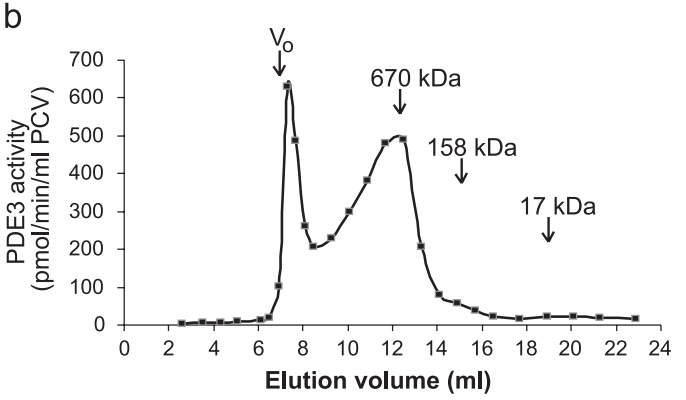

C

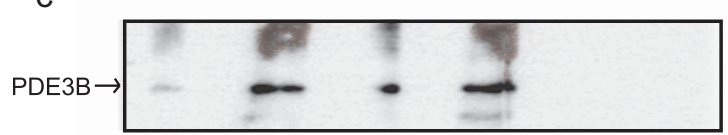

Cav-1 $\rightarrow$

\begin{tabular}{llllll}
\hline Start FT & IP & Start FT & IP & Start FT & IP
\end{tabular}

Elution vol (ml): $7 \quad 12 \quad 20$

Size $(\mathrm{kDa}): \quad>4000 \quad 670 \quad$ Non 
Figure 6

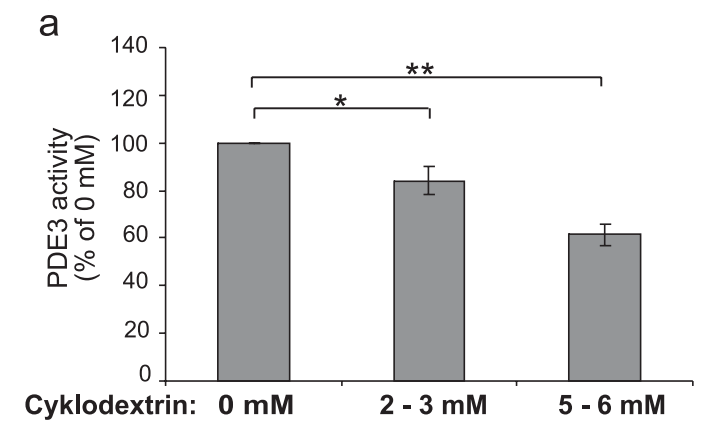

b

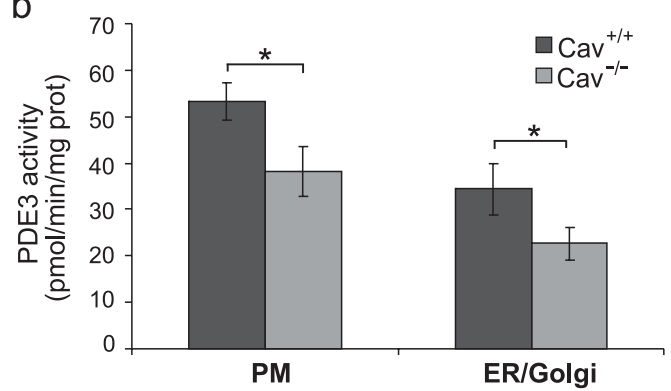

C

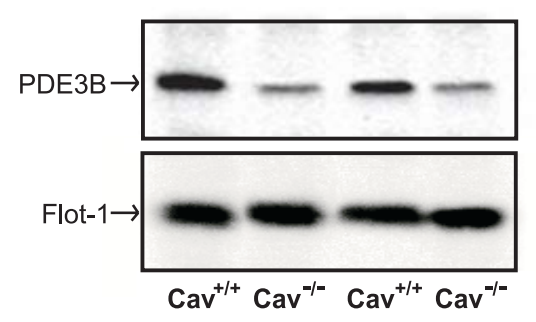


Figure 7

a

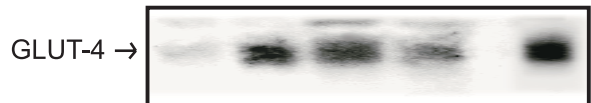

Cav-1 $\rightarrow$

\begin{tabular}{ccc}
\hline Ctrl Ins & Ins & Ins Neg Pos \\
OPC & Iso
\end{tabular}

OPC

b

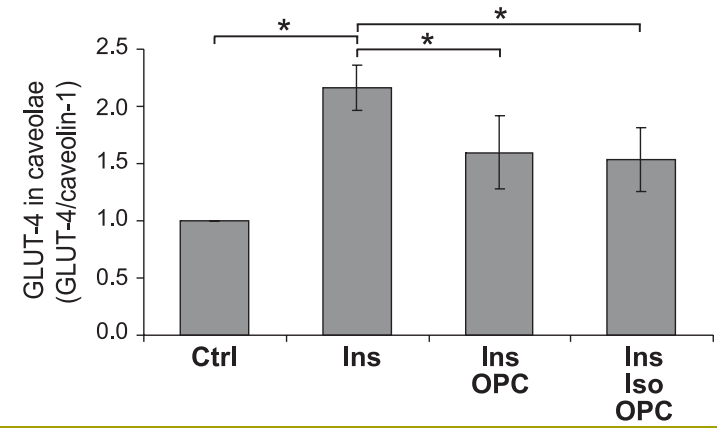

